\title{
Intellectual humility and the epistemology of disagreement
}

\author{
Duncan Pritchard ${ }^{1,2}$ (DD \\ Received: 16 October 2017 / Accepted: 16 November 2018 / Published online: 23 November 2018 \\ (c) The Author(s) 2018
}

\begin{abstract}
It is widely accepted that one strong motivation for adopting a conciliatory stance with regard to the epistemology of peer disagreement is that the non-conciliatory alternatives are incompatible with the demands of intellectual character, and incompatible with the virtue of intellectual humility in particular. It is argued that this is a mistake, at least once we properly understand what intellectual humility involves. Given some of the inherent problems facing conciliatory proposals, it is maintained that non-conciliatory approaches to epistemic peer disagreement are thus on much stronger dialectical ground than many suppose, including some defenders of this line. In particular, non-conciliatory proposals can resist the idea that epistemic peer disagreement directly weakens one's epistemic justification, as conciliatory views maintain. This means that the epistemic justification that our beliefs in this regard enjoy, and thus our knowledge, is more secure than conciliatory approaches to epistemic peer disagreement would suggest.
\end{abstract}

Keywords Epistemology of disagreement - Epistemology · Intellectual humility · Intellectual character

\section{Introductory remarks}

It is often suggested that there is an essential tension between taking a non-conciliatory approach to epistemic peer disagreement and the requirements of good intellectual character, especially in the sense of being suitably intellectually humble. According to the non-conciliatory approach, there is no requirement, from an epistemic point of view, to downgrade one's epistemic assessment of the target proposition in the

\footnotetext{
$凶$ Duncan Pritchard duncan.pritchard@ed.ac.uk

1 University of California, Irvine, Irvine, USA

2 University of Edinburgh, Edinburgh, UK
} 
light of disagreement with an epistemic peer. Now imagine that you and I are both (so we think anyway) roughly epistemic peers with regard to the subject matter in play, who both regard ourselves as having knowledge of our respective beliefs, and yet we surprisingly find ourselves disagreeing. If I stick to my opinion regardless, then aren't I inevitably displaying a worrying degree of epistemic arrogance, of a kind that is incompatible with the requirements of a good intellectual character? In particular, wouldn't this apparently dogmatic stance demonstrate that I am failing to exhibit the virtue of intellectual humility (an intellectual virtue that is widely thought to be essential to having good intellectual character)?

We can re-cast this tension in terms of epistemic justification, and thereby in terms of knowledge, at least to the extent that justification is at least necessary for knowledge. ${ }^{1}$ Prior to the disagreement, as epistemic peers one is (roughly anyway) equally justified in holding one's belief as one's counterpart is in holding her conflicting belief. Conciliatory approaches to the epistemology of peer disagreement hold that discovering the disagreement entails that one's justification for one's belief is at the very least weakened by the fact of the epistemic peer disagreement (if one's belief continues to count as justified at all). This means that such disagreements thus have the potential to undermine our knowledge. And we can regard this conciliatory approach as, in significant part at least, motivated by the tension just set out between non-conciliatory approaches to the epistemology of disagreement and the virtue of intellectual humility. For if one regarded oneself as no less justified in holding one's belief after discovering the epistemic peer disagreement as one was before, then doesn't that entail an epistemic arrogance on one's part, in that one is simply discounting the conflicting testimony supplied by one's epistemic peer?

I agree that this line of reasoning is very persuasive at first blush, but, as I hope to show, I think that it should be resisted. A key part of understanding why this line of reasoning is flawed is recognising that it is presupposing the wrong view of intellectual humility. In particular, once we characterise intellectual humility correctly, then we can account for how a subject can regard themselves as no less justified than they were before the epistemic peer disagreement without this entailing that they lack intellectual humility. This means that epistemic peer disagreement does not immediately weaken, still less completely undermine, our justification. Relatedly, such disagreements are not by their nature (at least potentially) knowledge-undermining either. Moreover, I think that the problems that face a conciliatory stance as regards epistemic peer disagreement have been given a far too easy ride precisely because there has been held to be this supposedly overarching difficulty afflicting the non-conciliatory line. ${ }^{2}$ The net effect of these points is that the non-conciliatory stance as regards epistemic peer disagreement is on much stronger ground than many suppose, including those who currently defend the view.

\footnotetext{
1 In what follows I will take it as given that knowledge entails justification.

2 What convinced me of this was an excellent talk by Stewart Cohen on the epistemology of disagreement at the Eidyn research centre at the University in Edinburgh a few years ago. He began by setting out this putative tension between non-conciliatory views and the demands of intellectual character and used this as a rationale for the philosophical project of solving the difficulties that afflict conciliatory views. The point was clear: this tension was meant to be toxic for non-conciliatory proposals, and hence the only game in town was to try to make sense of conciliatory proposals.
} 


\section{Unpacking the putative tension}

Let's start by setting out the putative tension between the non-conciliatory view and the requirements of good intellectual character in more detail. Notice first how I formulated the non-conciliatory view above, as the denial of a very weak version of the conciliatory view, in order to bring the issue that concerns us into sharpest relief. One might think that a conciliatory approach essentially involves epistemically requiring suspension of belief in the face of epistemic peer disagreement, but that's not my target. All that counts on my version of the conciliatory view is that the epistemic peer disagreement entails that one should lower one's epistemic assessment of the target proposition. In particular, one's belief enjoys less justification than it did before, which means in turn that it is less likely to amount to knowledge. Lowering one's epistemic assessment is consistent with one lowering it to the point of no longer believing it, and it is also consistent with one lacking any justification for the target proposition after the epistemic peer disagreement, but neither claim is entailed by the conciliatory view as I am interpreting it. $^{3}$

Accordingly, the non-conciliatory position on my reading demands that one is not required, from an epistemic point of view, to lower one's epistemic assessment of the target proposition. That's consistent with one in fact lowering this assessment, and also with one lowering it to the extent that one no longer believes the target proposition, but the point is just that there is no blanket epistemic requirement to do so simply as a result of the epistemic peer disagreement. Similarly, there is no blanket requirement to regard one's belief as enjoying less justification as a result of the epistemic peer disagreement, or to treat one's belief as being less likely to amount to knowledge. ${ }^{4}$

There is one important feature of the non-conciliatory position that I want to flag, since I think it is often overlooked. This is that it is entirely consistent with maintaining this position that one also holds that when faced with an epistemic peer disagreement one ought to be willing to reflect on the nature of one's epistemic situation with regards to the target proposition. Indeed, as I will explain below, I think that the requirements of intellectual character demand this (and much more besides). Crucially, however, reflecting on one's epistemic situation in this regard does not entail downgrading one's epistemic assessment of the target proposition, and thus regarding one's belief as less justified, and hence less likely to be knowledge, than before. (But why then reflect at all if your epistemic assessment of the target proposition is unaffected? We will come back to this point).

I should also flag that I have a particular sub-class of epistemic peer disagreements in mind (though as I will explain in a moment, I'm fairly confident most parties to this debate has this sub-class in mind too). To begin with, like most people in this literature I am specifically interested in cases of known epistemic peer disagreement (at least to the extent that our hero is aware of the disagreement with her epistemic peer anyway).

\footnotetext{
3 For some prominent defences of (versions of) conciliationism, see Christensen (2007), Elga (2007) and Feldman (2007).

4 This is part of the reason why I prefer calling the view in question 'non-conciliatory', as opposed to some of the other names that are given to the position, such as the 'steadfast' view (e.g., Christensen 2009). The latter, for example, seems to imply that one will stubbornly stick to one's guns regardless, and hence dialectically loads the die against the proposal from the off.
} 
In addition, I'm also specifically interested in epistemic peer disagreements where one's belief in the target proposition is considered. What I mean by this is that one has put some thought into the reasons in favour of this proposition, or at least could summon such reasons with ease if called upon to do so. This is important, because many of our beliefs are not considered beliefs in this sense. We just have them, and haven't really thought about their rational basis (nor could we easily summon such a rational basis if called upon to do so).

It's vital to keep considered beliefs apart from non-considered beliefs for our purposes because a non-conciliatory position, even granting the point just made about reflection, would not be very plausible as regards non-considered belief. After all, in such cases the epistemic peer disagreement is exposing the fact that one isn't sure what one's rational basis for the target proposition is, and so when faced with such disagreement it would usually be wise to downgrade one's epistemic assessment of it (if only temporarily), and thereby regard one's belief as less justified than before (and hence less likely to be knowledge), until this rational basis is clarified. So if we want to evaluate a plausible form of the non-conciliatory position, we should focus on cases of considered belief. (Interestingly, the stock examples of epistemic peer disagreemen$\mathrm{t}$ - such as calculated shares of the restaurant bill—nearly always involve what I'm here calling considered belief, so one might reasonably think that this distinction is already presupposed in the debate, but there's no harm in making it explicit anyway).

On the notion of epistemic peerhood, I am going to offer a rather loose and inclusive account, whereby it is sufficient that one regards one's disputant as being roughly on an epistemic par when it comes to the subject matter at hand. This means that one takes one's disputant to have roughly the same evidence as one does that's relevant to this dispute, is roughly equal in their cognitive capacities, and so on. Relatedly, prior to the disagreement at least, one's disputant is roughly as justified as you are in holding their respective belief, and both parties takes themselves to have knowledge. Notice that this doesn't entail that the disputant likewise regards you as an epistemic peer-in fact, she may think that she is one's epistemic superior in this regard. Moreover, note that this is a subjective account of epistemic peerhood, in that one could satisfy this condition and one's disputant not in fact be an epistemic peer. ${ }^{5}$

I have opted for this characterisation of epistemic peerhood because I think it is this version that stands the best chance of generating the putative tension between conciliatory views and the requirements of intellectual character. For example, we want to capture the idea, central to the putative tension, that our hero is under an epistemic requirement that they ought to be able to recognise from their point of view. A subjective account of epistemic peerhood is clearly going to be the most straightforward way of drawing this out.

Now we come to the requirements of intellectual character. I take good intellectual character to be that which is manifested by agents who have a well-developed and integrated set of intellectual virtues. We ought to have a good intellectual character, and if we fall short in this regard, then that's a failing on our part, at least from a purely epistemic point of view.

\footnotetext{
5 For more on the notion of epistemic peerhood, see Kelly (2005), though note that his characterization is not the same as the one just offered. See also Matheson (2015).
} 
There is a particular feature of good intellectual character that is doing the work when it comes to the putative problem with non-conciliatory views that we are focussing upon. This is the idea, now widely adopted, that intellectual humility is an intellectual virtue, and hence a constituent part of one's intellectual character. We should note at this juncture that there is a minority view that intellectual humility isn't an intellectual virtue, but even if that's so, it might still be a trait demanded of a good intellectual character, in which case the putative tension between the non-conciliatory position and a good intellectual character would still arise. ${ }^{6}$ In any case, we will grant that intellectual humility is an intellectual virtue for the purposes of this paper, given that it will only add strength to the opposition.

Keeping all the foregoing in mind, the general line of thought behind this putative tension is that it would be a sign of an absence of intellectual humility, thereby representing a failing of intellectual character, if one were to maintain one's epistemic assessment of the target proposition even in the face of epistemic peer disagreement. In particular, maintaining that one is just as justified in one's belief after the epistemic peer disagreement as before would represent a lack of intellectual humility. And doesn't that sound right? After all, given that we've granted that one regards the other as roughly an epistemic peer, wouldn't it be sheer intellectual arrogance to maintain one's epistemic assessment of the target proposition regardless (where intellectual arrogance is obviously an indication that one lacks intellectual humility)? In particular, isn't to maintain one's epistemic assessment of the target proposition in these circumstances simply an expression of one's brute dogmatic conviction that one is entitled to one's viewpoint, even though one's epistemic peer disagrees? How can this not be a manifestation of intellectual arrogance (and hence a lack of intellectual humility) $?^{7}$

\section{Humility, intellectual or otherwise}

I want to suggest that, contrary the line of argument just presented, the right account of intellectual humility is entirely compatible with taking a non-conciliatory line on epistemic peer disagreement. (Indeed, as we will note in due course, another account of intellectual humility that is popular in the literature, but which I think is far less plausible than the one defended here, might well be compatible with a non-conciliatory line as well, albeit less obviously so. And a third account of intellectual humility might not be amenable to setting up the putative tension in the first place). In order to see this, we first need to consider humility more generally.

\footnotetext{
${ }^{6}$ For a very intersting pushback on the idea of intellectual humility as an intellectual virtue, see Bloomfield (2017a). See also Bloomfield (2017b).

7 This point is often put in terms of an epistemic symmetry claim. See, for example, Kelly (2005). Roughly, the thought is that epistemic peerhood ensures that one is on an epistemic par (or at least should regard one's disputant as being on an epistemic par) with one's disputant. Accordingly, on what rational basis can one dismiss the opposing viewpoint? And if there is no rational basis for doing this, then surely that entails that one is simply being dogmatic.
} 
There are three main ways of thinking about humility. ${ }^{8}$ According to the first line-which I will call the ignorance proposal - humility involves having an inaccurate conception of one's achievements and abilities, one that treats them as significantly more deficient than they in fact are. To be humble on this view is to have a downgraded view of one's achievements and abilities. ${ }^{9}$ This certainly seems to be closest to the folk conception of humility, in that we tend to suppose that the genuinely humble don't merely behave as if they have a downgraded conception of their achievements and abilities (which is compatible with this being a mere pretence), but that they really do imagine that they are somehow 'lesser' than they in fact are.

According to the second line-what I will call the accuracy proposal-humility involves having a correct assessment of the extent of one's achievements and abilities, albeit one that in the process involves recognising one's inherent fallibility and limitations. One needs to in a sense 'own' one's limitations. Lack of humility, in contrast, leads to one neglecting to recognise these inherent limitations and failings.

According to the third line-which I will call the non-egotist proposal-humility involves lacking those characteristic dispositions involved in excessive self-regard, such as conceit, arrogance, haughtiness, and so on. In contrast, on this view, humility involves the essentially other-directed dispositions of, for example, helping others behind the scenes without seeking the credit for doing so. This is in contrast to the previous two proposals which are in effect self-regarding stances, in that they are focussed on one's own assessment of one's achievements and abilities. Note that it is important to the non-egotist proposal that these other-regarding dispositions arise out of a genuine respect for others, and a love of the greater good more generally. For example, superficially displaying the relevant dispositions for, say, merely strategic reasons would not be a genuine manifestation of humility. In this the virtue of humility is like other virtues (and unlike mere skills or faculties), in that its manifestation involves characteristic dispositions that are rooted in appropriate motivational states.

These are three general approaches to humility, and hence within each approach we could delineate more than one position that falls under this heading. What's presently important is just that for each of these three approaches we can determine a corresponding proposal that is specifically focussed on intellectual humility. ${ }^{10}$ According to the ignorance proposal, intellectual humility will involve having an inaccurate, in the sense of degraded, conception of one's intellectual achievements and cognitive abilities. According to the accuracy proposal, intellectual humility will involve having a correct assessment of one's intellectual achievements and cognitive abilities,

\footnotetext{
${ }^{8}$ I articulate this three-way characterization of humility, and thus of intellectual humility, in Kallestrup and Pritchard (2017) and Pritchard (forthcoming a).

9 See especially Driver (1989). See also Brennan (2007) for a related proposal (though here it is not inaccuracy as such but rather holding oneself to higher standards than one would ever hold others too).

10 Note that I am here following many others in the literature in taking it as given that intellectual humility is a sub-species of humility more generally. I don't myself find that claim controversial, but Paul Bloomfield and Michael Lynch have independently put to me in conversation that they regard such an assumption as controversial. (In Lynch's case at least this is because he regards intellectual humility as a theoretical term of art, which is used in ways that don't altogether track our everyday conception of humility). If that were right, then of course one ought not to move directly from an account of humility to an account of specifically intellectual humility.
} 
and thereby recognising one's inherent intellectual limitations. ${ }^{11}$ Finally, according to the non-egotist proposal, intellectual humility will involve lacking the characteristic dispositions involved in excessive intellectual self-regard, such as conceit, intellectual arrogance, and so on. Relatedly, it will involve manifesting such dispositions as an openness to other people's viewpoints, a willingness to listen to counterevidence, and the inclination to change one's mind if the epistemic facts require it, where such dispositions are rooted in appropriate motivational states (i.e., a genuine intellectual respect for others, and a love of the intellectual good more generally). ${ }^{12,13}$

\section{The putative tension, redux}

I want to suggest that of these three general approaches to humility, and thus intellectual humility, it is the non-egoist proposal that we should prefer. Crucially, however, this way of thinking about intellectual humility will not generate the putative tension with the non-conciliatory view about epistemic peer disagreement. (Indeed, as we will see, arguably neither of the other two proposals will generate this tension either, at least once the details are teased out, though this is not immediately obvious).

Interestingly, only the accuracy and non-egotist proposals are plausible contenders when it comes to the issue that we are concerned with. This is because we have granted to the opposition that intellectual humility is an intellectual virtue, as this is an important part of the case that's being made for the inherent tension between non-conciliatory views and the demands of intellectual character. But it simply isn't credible that an intellectual virtue could be constituted in terms of an inaccurate conception of oneself. Intellectual virtues, after all, are characterised by their epistemic

\footnotetext{
${ }^{11}$ For two important developments of this type of account of intellectual humility in the recent literature, see the doxastic proposal offered by Church (2016) and the limitations-owning proposal offered by Whitcomb et al. (2017). Note, however, that there are important differences between these two proposals, though they are not relevant for our current purposes. For a useful discussion of these differences, see Barrett and Church (2016).

12 See Roberts and Wood $(2003,2007)$ for two important defences of this approach. See also Priest (2017) and Tanesini (2016).

13 Note that on this proposal, intellectual humility will entail open-mindedness, a cognitive trait which is itself often said to be an intellectual virtue. Indeed, one might be tempted as a result to treat these two intellectual virtues as simply manifestations of a single general virtue. I think that this would be a mistake, however, as one can be open-minded without thereby being intellectually humble. For example, if one has heard the case for a certain opposing position before, then it is consistent with the demands of open-mindedness that one dismisses it out of hand and declines to listen to it presented again. But intellectual humility might well require one to listen, out of one's intellectual respect for others. More broadly, open-mindedness needn't be rooted in the motivational state of intellectually respecting others (and the truth more generally) as intellectual humility is, and hence one could exhibit the former without thereby exhibiting the latter. Indeed, it isn't clear to me that the dispositions associated with open-mindedness need to be associated with virtuous motivational states at all. For sure, the open-minded person needs to care about the truth, but I don't see why this concern for the truth couldn't be purely strategic-e.g., to further one's practical ends (scientific fame, for example) - in contrast to the virtuous motivational states behind intellectual humility, which as we noted above could not be purely strategic in this way. (As we might put the point, the intellectually virtuous person values the intellectual goods in a final, non-instrumental, fashion). If that's right, then intellectual humility and open-mindedness are bound to come apart, as only the former is a genuine intellectual virtue. For two recent discussions of open-mindedness, see Riggs (2010) and Baehr (2011).
} 
credentials, and an intellectual 'virtue' that essentially involved inaccuracy would inevitably be lacking in epistemic pedigree. ${ }^{14}$ (Moreover, notice that on this view it would appear to follow that having an accurate conception of one's epistemic standing would be an intellectual vice, which is a somewhat bizarre entailment of the position). In any case, if intellectual humility is not a virtue, then it wouldn't obviously have anything essential to do with the demands of intellectual character, so there would be a lacuna in the argument that there is an inherent tension between non-conciliatory proposals and manifesting good intellectual character. So whatever else one might say in opposition to the ignorance proposal for intellectual humility, it is out of the running for our purposes, as it can't be employed to create the putative tension between non-conciliatory proposals regarding epistemic peer disagreement and the demands of intellectual character.

With this in mind, it is important to note that if any of the remaining accounts of intellectual humility is generating the putative tension between non-conciliatory views about epistemic peer disagreement and the demands of intellectual character, then it is the accuracy proposal (though the ignorance proposal would be a more dramatic way of staging this tension). The problem is that if one sticks to one's commitment to the target proposition in the face of an epistemic peer disagreement, and hence regards one's belief as just as justified as before, then one is not, it seems, 'owning' one's fallibility at all, but rather ignoring it. One is thus lacking in the virtue of intellectual humility, and that's a failing of intellectual character. (As we will see below, there may be a way of understanding the accuracy account such that it doesn't have this consequence, but if so, then all that would follow is that one can't appeal to this account in order to motivate the tension between non-conciliatory views and intellectual character that concerns us).

In contrast, the non-egotist account of intellectual humility isn't necessarily in tension with a non-conciliatory position at all. What's important to this account is specifically the kinds of dispositions you manifest - whether you are open to changing your opinions, whether you are willing to reflect on your evidence and the counterevidence presented by others, whether you are respectful of other people's views, and so on-and whether those dispositions are rooted in the appropriate motivational states. But one could well manifest all of these dispositions along with the relevant motivational statues and still be as committed to the target proposition as before. In particular, one could manifest all these dispositions in the appropriate way while still regarding one's belief as no less justified than prior to the epistemic peer disagreement, and hence no less likely to amount to knowledge. Moreover, in maintaining one's commitment to the target proposition in this fashion one wouldn't be displaying intellectual arrogance at all but rather intellectual humility, and hence one's non-conciliatory stance would not be in conflict with the demands of intellectual character.

Now one might object at this point that if one isn't epistemically downgrading one's assessment of the target proposition, and thereby regarding one's belief as less justified than before the epistemic peer disagreement, then wouldn't that make the manifestation of these dispositions somewhat fake? I don't think that this follows at

\footnotetext{
14 I'm sceptical of any bona fide virtue being manifested by inaccurate dispositions, and thus with the idea of humility in general being a virtue in this sense, but that's not an issue that we need concern ourselves with just now.
} 
all. This is a good juncture to return to a point I made earlier when I said that it is entirely consistent with a non-conciliatory view that one ought to reflect on the nature of one's evidence in response to an epistemic peer disagreement. Now one might be puzzled by this because one holds that if one is not downgrading one's epistemic assessment of the target proposition in light of the disagreement - even temporarily - then any such reflection is just a fake show. We thus have a parallel concern to the one just noted, albeit now specifically focussed on the subject's reflection on their epistemic position while maintaining their view. Again, however, I think the worry is unfounded, and I think that the non-egotist account of intellectual humility accurately captures why.

In being willing to reflect on one's evidence in light of the epistemic peer disagreement, one is manifesting one's good intellectual character, and one's intellectual humility in particular. Moreover, if this reflection is rooted in a good intellectual character, and thus arises out of the distinctive motivational states that are constitutive of such a character (i.e., a love for the truth), then there will be nothing fake at all about this process of refection. Indeed, it could well result in one realising that there is something amiss with the evidence one has for the target proposition which one has hitherto overlooked, in which case as an intellectually virtuous subject one will be willing to revise one's epistemic assessment of this proposition accordingly, and thereby regard oneself as less justified in believing the target proposition than before the epistemic peer disagreement, and hence less likely to have knowledge. ${ }^{15}$

I noted earlier that I thought good intellectual character not only demands that one reflects on one's evidence in light of epistemic peer disagreement, but much also else besides. We can see why by considering what someone with the virtue of intellectually humility would do in response to an epistemic peer disagreement, at least on the nonegotist proposal. For besides reflecting on the nature of their evidence, she will also manifest a range of other distinctive behaviours, such as considering the other person's reasons for thinking otherwise, being willing to respectively discuss the issue further, and all the time showing a willingness to change her mind if that is demanded by the evidence. Crucially, however, one can manifest all of these behaviours - along with the corresponding motivational states-while nonetheless maintaining one's conviction in the target proposition, and hence regarding oneself as no less justified in one's belief than before the epistemic peer disagreement. And since these behaviours are arising out of appropriate motivational states for an intellectual virtue, there is nothing remotely fake about responding in this way.

We have seen that of the three main ways of thinking about intellectual humility, only one of them - the accuracy approach — generates even a prima facie basis for thinking that there is an essential tension between non-conciliatory views and intellectual humility. Moreover, there is one way of thinking about intellectual humility- the non-egotist approach-such that there need be no essential tension of this kind at all. Still, one might argue that this is beside the point because it is the accuracy account of intellectual humility that creates this tension that is the correct position to hold. With this in mind, let me explain why I think the non-egotist account of intellectual humility is to be preferred over the accuracy account.

15 Going back to an earlier point - see endnote 4-this is why, by the way, it is important to call the view 'non-conciliatory' rather than 'steadfast'. 
There are two scenarios that we should consider. In the most straightforward case we imagine someone who has an accurate conception of her (ordinary) cognitive achievements and abilities, but who is nonetheless lacking in the distinctive otherregarding dispositions and motivational states as set out by the non-egotist account. This is entirely possible, after all. Perhaps she fully recognises her limitations, but is nonetheless dismissive of others regardless, and hence acts in an intellectually arrogant way. And of course being intellectual arrogant is incompatible with being intellectually humble. The point is that while normally recognising one's epistemic limitations leads to certain distinctively humble other-regarding dispositions, it doesn't have to.

We can bring this point into sharper relief by imagining a second case where the subject is not an ordinary individual from an epistemic point of view, but rather intellectually exceptional. This person might well recognise her inherent fallibility, but at the same time also recognise that she is far less fallible than most of the ordinary folk. On the accuracy view, what would prevent her from being quite explicit about her epistemic superiority over those around her, and hence being dismissive of their opinions as a result? After all, that would be entirely compatible with embracing her fallibility, given that her intellectual superiority means that she is far less fallible than those around her. The crux of the matter is that in this scenario 'owning one's limitations' could be entirely compatible with being dismissive of others and hence being intellectually arrogant-she is intellectually superior, after all.

Now one response that someone who defends the accuracy view might offer to such cases is to insist that genuinely 'owning' one's intellectual limitations entails exhibiting the other-regarding dispositions set out by the non-egotist proposal, such that the two scenarios just described would not be bona fide cases of 'owning' one's fallibility. ${ }^{16}$ I really don't see why this should be the case-especially when it comes to someone who is genuinely intellectually superior and fully recognises this fact-but we do not need to argue the point for our purposes. This is because if this is the way we are to understand the view, then, at least in terms of the putative tension between nonconciliatory views and the demands of intellectual character, there is no substantive difference between this account of intellectual humility and the non-egotist proposal. Accordingly, if the non-egotist account of intellectual humility doesn't generate this tension, then neither will the accuracy account on this reading. So, again, the case for this putative tension collapses.

Interestingly, once we notice that the accuracy account - insofar as it is significantly distinct from the non-egotist account anyway-is compatible with failing to display the characteristic dispositions and motivational states of the intellectual humble, then we also realise that it doesn't necessarily generate an essential tension with nonconciliatory views either. It seemed to above because we were taking it as given

\footnotetext{
16 This does indeed seem to be roughly the way this proposal is understood by Whitcomb et al. (2017). What complicates the matter, however, is that Whitcomb et al. effectively mischaracterize what I am here called the non-egotist position as the claim that one should be disposed to have a "low concern for one's own intellectual status and entitlements." (6) But this is at most a consequence of the view, rather than being the view itself. Indeed, given that this way of characterizing the position is so ego-centric, it is arguably not even that. The nub of the matter is that Whitcomb et al. misidentify what is key to the non-egotist position, which is the way in which it is grounded in an intellectual concern for others and for the truth more generally. Accordingly, it is far from clear that their presentation of (what I am here calling) the accuracy view really does fully capture the kinds of cases that drive the non-egotist view.
} 
that having an accurate conception of one's epistemic capacities meant being willing to automatically downgrade one's epistemic assessment of the target proposition in light of an epistemic peer disagreement, and thereby regard one's belief in the target proposition as less justified (and hence less likely to be knowledge) as a result. But since one can satisfy the requirements of the accuracy account even while being dismissive of others and hence intellectually arrogant (as in the case where one fully recognises that one is intellectually superior to those around one), then obviously this entailment doesn't follow at all. (Of course, we have seen that not downgrading one's epistemic assessment of the target proposition in light of an epistemic peer disagreement is also compatible with being intellectually humble). So the putative tension between non-conciliatory views and the demands of intellectual character are unravelling even granting that we opt for the problematic accuracy account of intellectual humility.

Finally, notice that having an accurate conception of one's epistemic standing isn't necessary for one to manifest intellectual humility anyway. Perhaps one is inclined to underestimate one's epistemic standing. Would that preclude one from manifesting intellectual humility? I don't see why. The crucial thing is whether one manifests the distinctive behaviours and corresponding motivational states described by the nonegotist proposal, behaviours and motivational states that one could manifest regardless of whether one's epistemic assessment of oneself is accurate. Having an accurate conception of one's epistemic standing - or, for that matter, an inaccurate one-is not an essential requirement for one to manifest intellectual humility. What is important is displaying those distinctive behaviours and corresponding motivational states associated with being intellectually humble.

\section{The state of play}

So where does this leave us in terms of the state of play regarding the conciliatory/nonconciliatory debate about the epistemology of peer disagreement? My sense is that even most defenders of non-conciliatory approaches are inclined to accept that there is at least a prima facie tension between their view and the requirements of intellectual character, and hence that the non-conciliatory stance is on the back foot from the off. Accordingly, if I'm right and there is in fact no tension of this kind, then it follows that non-conciliatory views are on a much stronger footing, even by the lights of some of their defenders. Relatedly, my suspicion is that a lot of commentators feel pulled towards a conciliatory position with regard to the epistemology of peer disagreement precisely because they think that the problems that afflict the non-conciliatory proposal-such as the putative tension with the demands of intellectual character that we have discussed - are fatal to view. If the position can deal with these putative problems, as I have argued, then this dramatically changes the dialectical landscape, in that non-conciliatory stances with regard to the epistemology of peer disagreement are now viable. ${ }^{17}$

\footnotetext{
17 See also Pritchard (2012), where I defend non-conciliatory proposals from so-called 'track-record' objections, as pressed, for example, by Elga (2007).
} 
Moreover, the problems facing conciliatory approaches to epistemic peer disagreement are now brought into sharper relief. After all, this is not a cost-free proposal in that it brings with it difficulties of its own, difficulties that are often glossed over given that it is taken as granted that the alternative non-conciliatory stance is in a worse dialectical position. These include, for example, the notorious problem that the proponent of a conciliationary approach should be willing to downgrade her confidence in the conciliatory proposal itself, given that this is philosophically controversial. ${ }^{18}$ The difficulties facing conciliatory approaches have been thought to be of a kind that should be borne precisely because the problems that face non-conciliatory approaches have been treated as so severe. If it turns out that that the non-conciliatory approach to epistemic peer disagreement is on much stronger ground than many supposed-including proponents of the position - then the difficulties that afflict the conciliatory approach suddenly take on a new aspect. The upshot is that when it comes to epistemic peer disagreement, there is much less of a challenge to the justification of our beliefs, and thus our knowledge, than many have hitherto supposed. ${ }^{19,20}$

Open Access This article is distributed under the terms of the Creative Commons Attribution 4.0 International License (http://creativecommons.org/licenses/by/4.0/), which permits unrestricted use, distribution, and reproduction in any medium, provided you give appropriate credit to the original author(s) and the source, provide a link to the Creative Commons license, and indicate if changes were made.

\section{References}

Baehr, J. (2011). The structure of open-mindedness. Canadian Journal of Philosophy, 41, 191-213.

Barrett, J., \& Church, I. M. (2016). Intellectual humility. In E. L. Worthington Jr, D. E. Davis \& J. N. Hook (Eds.), Handbook of humility: Theory, research, and applications (Chap. 4). Routledge.

Bloomfield, P. (2017a). Humility is not a virtue. In M. Alfano, M. Lynch \& A. Tanesini (Eds.), The Routledge handbook of philosophy of humility.

Bloomfield, P. (2017b). Virtues as excellences, manuscript.

Brennan, J. (2007). Modesty without illusion. Philosophy and Phenomenological Research, 75, 111-128.

Christensen, D. (2007). Epistemology of disagreement: The good news. Philosophical Review, 116, $187-217$.

Christensen, D. (2009). Disagreement as evidence: The epistemology of controversy. Philosophy Compass, 4(5), 756-767. https://doi.org/10.1111/j.1747-9991.2009.00237.x.

\footnotetext{
18 See Elga (2010) for some pushback to this line of thought.

19 Indeed, I would extend this point to disagreements more generally. For example, I have argued elsewhere that so-called 'deep' disagreements involving fundamental clashes of worldview do not license epistemic incommensurability and thereby epistemic relativism, and hence cannot be used to motivate the sceptical thought that we have far less bona fide justification for our beliefs, and thus less knowledge, than we ordinarily suppose. See Pritchard (2009, 2010, 2018a). See also Pritchard (2018b), where I argue that the negative epistemic import of some kinds of disagreement is moot precisely because, properly understood, the conflicts in play are either mischaracterized or in a certain sense fake.

20 I am grateful to four anonymous referees from Synthese for their detailed comments on an earlier version of this paper. Thanks also to David Bakhurst, Paul Bloomfield, Ian Church, Stewart Cohen, Casey Johnson, Michael Lynch, Erik Olsson, and Maura Priest for helpful discussion of topics related to this paper. This paper has benefitted from three grants awarded by the Templeton Foundation, all of them for projects hosted at the University of Edinburgh's Eidyn research centre. These are: (i) the 'Virtue Epistemology, Epistemic Dependence and Intellectual Humility' project, which was itself part of the wider 'Philosophy and Theology of Intellectual Humility Project' hosted by Saint Louis University; (ii) the 'Intellectual Humility MOOC' project; and (iii) the 'Philosophy, Science and Religion Online' project.
} 
Church, I. (2016). A doxastic account of intellectual humility. Logos \& Episteme, 4, 413-433.

Driver, J. (1989). The virtues of ignorance. Journal of Philosophy, 86, 373-384.

Elga, A. (2007). Reflection and disagreement. Noûs, 41, 478-502.

Elga, A. (2010). How to disagree about how to disagree. In R. Feldman \& T. Warfield (Eds.), Disagreement (pp. 175-186). Oxford: Oxford University Press.

Feldman, R. (2007). Reasonable religious disagreements. In L. Antony (Ed.), Philosophers without Gods (pp. 194-214). Oxford: Oxford University Press.

Kallestrup, J., \& Pritchard, D. H. (2017). Intellectual pride and intellectual humility. In J. A. Carter \& E. Gordon (Eds.), Pride (pp. 69-78). Totowa: Rowman \& Littlefield.

Kelly, T. (2005). The epistemic significance of disagreement. In T. S. Gendler \& J. Hawthorne (Eds.), Oxford studies in epistemology (Vol. 1). Oxford: Oxford University Press.

Matheson, J. (2015). Disagreement and epistemic peers. Oxford handbooks online. http:// www.oxfordhandbooks.com/view/10.1093/oxfordhb/9780199935314.001.0001/oxfordhb9780199935314-e-13.

Priest, M. (2017). Intellectual virtue: An interpersonal theory. Ergo. https://doi.org/10.3998/ergo.12405314. 0004.016.

Pritchard, D. H. (2009). Defusing epistemic relativism. Synthese, 166, 397-412.

Pritchard, D. H. (2010). Epistemic relativism, epistemic incommensurability and wittgensteinian epistemology. In S. Hales (Ed.), The Blackwell companion to relativism (pp. 266-285). Oxford: Blackwell.

Pritchard, D. H. (2012). Disagreement, scepticism, and track-record arguments. In D. Machuca (Ed.), Disagreement and scepticism (pp. 150-168). London: Routledge.

Pritchard, D. (2018a). Wittgensteinian hinge epistemology and deep disagreement. Topoi. https://doi.org/ 10.1007/s11245-018-9612-y.

Pritchard, D. H. (2018b). Disagreement, of belief and otherwise. In C. Johnson (Ed.), Voicing dissent: The ethics and epistemology of making disagreement public (pp. 22-39). London: Routledge.

Pritchard, D. H. (Forthcoming a). Educating for intellectual humility and conviction. In D. Bakhurst (Ed.), Teaching and learning. Oxford: Blackwell.

Riggs, W. (2010). Open-mindedness. Metaphilosophy, 41, 172-188.

Roberts, R. C., \& Wood, W. J. (2003). Humility and epistemic goods. ch. 11. In M. DePaul \& L. Zagzebski (Eds.), Intellectual virtue: Perspectives from ethics and epistemology. Oxford: Oxford University Press.

Roberts, R. C., \& Wood, W. J. (2007). Intellectual virtues: An essay in regulative epistemology. Oxford: Oxford University Press.

Tanesini, A. (2016). Intellectual humility as attitude. Philosophy and phenomenological research (Online First, https://doi.org/10.1111/phpr.12326).

Whitcomb, D., Battaly, H., Baehr, J., \& Howard-Synder, D. (2017). Intellectual humility: Owning our limitations. Philosophy and Phenomenological Research, 94, 509-539. 